\title{
A NEW GROUP OF ENTEROBACTERIA, POSSIBLY A NEW CITROBACTER SP.
}

\author{
E. Valerie Booth and Sheila McDonald \\ Department of Microbiology, Sunnybrook Hospital, Toronto
}

THE isolation of enteric bacteria that do not conform to any of the recognised genera and species is common in clinical microbiology departments. The family Enterobacteriaceae consists of a continuous spectrum of closely related types and is difficult to subdivide. However, Edwards and Ewing (1962) showed that most cultures can be allotted to groups on the basis of similarity of biochemical properties. These groups constitute the currently accepted genera and species in the family.

When a number of isolates from different sources give the same biochemical pattern and this does not fit any of the recognised groups there are two possible explanations. A single aberrant strain may have become locally prevalent as a result of cross-infection, or the isolates may represent a distinct but not generally recognised group of enterobacteria. This paper describes the investigation of such a group of organisms.

\section{MATERIALS AND METHODS \\ Organisms}

Forty strains isolated between April 1968 and September 1969 were subjected to detailed biochemical study and to limited serological investigation; 28 of them were isolated in this laboratory from routine specimens received from in-patients, nine were from patients in a nearby rehabilitation centre, and the remaining three were received from other hospitals. All but one of the isolates were from different patients; the one duplicate was included because it had a distinct antibiotic sensitivity pattern and distinct biochemical properties.

Fourteen stock cultures of biochemically typical members of accepted genera and species of enteric bacteria were used in the serological studies. These organisms were Escherichia coli, Edwardsiella tarda, Salmonella typhi, Salm. heidelberg, Citrobacter freundii, Enterobacter aerogenes, Ent. cloacae, Serratia marcescens, Proteus mirabilis, Pr. vulgaris, Pr. morganii and one strain representing each of the Arizona, Klebsiella and Providencia groups.

\section{Bacteriological investigations}

The biochemical tests used in the preliminary studies of the organisms were those in routine use in this laboratory. Later, additional tests were carried out so that the pattern of reactions could be more easily compared with those reported by Edwards and Ewing and other workers. All tests were incubated at $37^{\circ} \mathrm{C}$.

Indole production, motility and hydrogen sulphide production were detected in the composite SIM medium (Baltimore Biological Laboratories). This is a semi-solid nutrient agar containing peptone, ferrous ammonium sulphate and sodium thiosulphate. The medium was inoculated in duplicate by the stab method. Indole production was demonstrated by adding Kovacs' reagent after $24 \mathrm{hr}$. Motility was shown by outgrowth of the organisms from the stab line. Hydrogen sulphide production was shown by blackening of the

Received 29 Jan. 1971; accepted 15 Feb. 1971.

J. MED. MICROBIOL.-VOL. 4 (1971) 
medium. Cultures were observed for 5 days. Triple sugar iron agar (TS1 agar, Difco) was also used for the detection of hydrogen sulphide; positive results were indicated by blackening of the medium. The cultures were incubated for 5 days.

Decarboxylase tests. Decarboxylation of lysine and ornithine was detected in 1-ml volumes of the modified Falkow medium described by Cowan and Steel (1965), with a layer of mineral oil added before autoclaving to prevent oxidation. The cultures were examined daily for 4 days.

Arginine desimidase was detected in Thornley's (1960) medium. A layer of mineral oil was added before autoclaving to prevent oxidation. The cultures were examined daily for 5 days.

Nitrate reduction was carried out in nitrate broth (Difco). The presence of nitrite was shown by the Griess-Ilosvay method after incubation for $24 \mathrm{hr}$.

Carbohydrate fermentation tests were carried out in phenol red broth base (BBL) containing 1 per cent. of the following carbohydrates: adonitol, arabinose, dulcitol, inositol, lactose, maltose, mannitol, raffinose, rhamnose, salicin, sorbitol or sucrose. A Durham's tube was included in the glucose medium. These tests were incubated for 7 days before being regarded as negative.

Other biochemical tests. The following tests were carried out as described by Cowan and Steel. The method followed when alternatives are given is indicated in parentheses: oxidation of gluconate (method 2); utilisation of malonate in phenylalanine-malonate broth (Difco); utilisation of citrate in Simmons' citrate agar (Difco); phenylalanine deamination (method 2) in phenylalanine agar (Difco) after 2 days; urease production (method 1) in a medium prepared from urea agar base concentrate (Difco), observed daily for 5 days; gelatin liquefaction (method 2) observed daily for 7 days; methyl red and Voges-Proskauer reactions in MR-VP broth (Difco), Barritt's method for the Voges-Proskauer reaction and both tests read after 2 days; oxidase (Kovacs' method).

Antibiotic sensitivity tests were carried out on Mueller-Hinton medium with filter-paper discs (BBL) containing the following: ampicillin $2 \mu \mathrm{g}$ and $10 \mu \mathrm{g}$, cephaloridine $30 \mu \mathrm{g}$, chloramphenicol $5 \mu \mathrm{g}$, colistin $10 \mu \mathrm{g}$, nitrofurantoin $100 \mu \mathrm{g}$, kanamycin $5 \mu \mathrm{g}$ and $30 \mu \mathrm{g}$, nalidixic acid $5 \mu \mathrm{g}$, gentamicin $2 \mu \mathrm{g}$ and $10 \mu \mathrm{g}$, streptomycin $2 \mu \mathrm{g}$ and $10 \mu \mathrm{g}$. Minimum inhibitory concentrations of cephalosporin $\mathrm{C}$ were determined by incorporating the antibiotic in plates of brain heart infusion agar (BBL).

\section{Serological investigations}

Preparation of antisera. O-antigen suspensions were made from four strains (NCTC no. $10768,10769,10770$ and 10771) selected from the group of organisms under investigation. Each organism was grown on a nutrient agar plate and the growth was suspended in normal saline and boiled for $2 \mathrm{hr}$. Suspensions containing approximately $10^{8}$ organisms per ml were used to immunise rabbits. Intravenous injections of $0.5 \mathrm{ml}, 1 \mathrm{ml}, 2 \mathrm{ml}$, and two of $4 \mathrm{ml}$ were given at intervals of 4 days and a test bleeding was done 4 days after the final injection to determine the antibody titre. The four organisms selected for the preparation of $\mathrm{H}$-antisera were all actively motile, and their motility was enhanced by passage through a Craigie tube. An equal volume of 0.6 per cent. formol-saline was added to an overnight culture of each organism in Trypticase Soy Broth (BBL) and these suspensions were used to immunise rabbits as described above.

Preparation of suspensions for agglutination tests. Suspensions for O-agglutination were prepared by suspending the growth from a nutrient agar plate in normal saline and boiling the suspension for $2 \mathrm{hr}$. Eight of the 40 strains were found to be auto-agglutinable when suspensions were prepared in this way. O-suspensions from these cultures were made by centrifuging an overnight broth culture of the organisms and suspending the deposit in absolute alcohol. The suspension was centrifuged and the organisms were resuspended in saline. The antigen was then heated at $45^{\circ} \mathrm{C}$ for $1 \mathrm{hr}$. $\mathrm{H}$-antigen suspensions were made by adding an equal volume of 0.6 per cent. formol-saline to an overnight culture of organisms in Trypticase Soy Broth. 
Procedure for agglutination tests. Each antiserum was tested against the antigen suspensions of the 40 strains under investigation. Three dilutions were used: a low dilution ranging from 1 in 20 to 1 in 50; a medium dilution that ranged from 1 in 100 to 1 in 1000 , depending on the titre of the antiserum; a high dilution that was approximately the titre of the antiserum. Organisms were considered to have homologous antigens only if they were agglutinated to the titre of the appropriate antiserum.

TABLE I

Characters of 40 strains of the organism under investigation

\begin{tabular}{|c|c|c|c|c|c|}
\hline \multirow{2}{*}{ Test } & \multicolumn{3}{|c|}{$\begin{array}{l}\text { No. of strains } \\
\text { giving reaction }\end{array}$} & \multirow{2}{*}{$\begin{array}{c}\text { Group } \\
\text { reaction }\end{array}$} & \multirow{2}{*}{ Comments } \\
\hline & + & $(+)$ & - & & \\
\hline $\begin{array}{l}\text { Motility } \\
\text { Indole production } \\
\mathrm{H}_{2} \text { S production in SIM } \\
\mathrm{H}_{2} \text { S production in TS1 } \\
\text { Gluconate oxidation } \\
\text { Malonate utilisation } \\
\text { Citrate utilisation } \\
\text { Phenylalanine deamination } \\
\text { Urease production } \\
\text { Gelatin liquefaction } \\
\text { Lysine decarboxylase } \\
\text { Ornithine decarboxylase } \\
\text { Arginine desimidase } \\
\text { Methyl red reaction } \\
\text { Voges-Proskauer reaction } \\
\text { Oxidase production } \\
\text { Nitrate reduction } \\
\text { Gas from glucose } \\
\text { Acid produced from: } \\
\text { adonitol } \\
\text { arabinose } \\
\text { dulcitol } \\
\text { inositol } \\
\text { lactose } \\
\text { maltose } \\
\text { mannitol } \\
\text { raffinose } \\
\text { rhamnose } \\
\text { salicin } \\
\text { sorbitol } \\
\text { sucrose }\end{array}$ & $\begin{array}{r}37 \\
40 \\
0 \\
0 \\
0 \\
39 \\
40 \\
2 \\
13 \\
0 \\
0 \\
40 \\
13 \\
40 \\
0 \\
0 \\
39 \\
39 \\
40 \\
40 \\
10 \\
0 \\
27 \\
40 \\
40 \\
0 \\
39 \\
6 \\
40 \\
14\end{array}$ & $\begin{array}{r}0 \\
\ldots \\
40 \\
2 \\
\ldots \\
0 \\
0 \\
0 \\
6 \\
0 \\
2 \\
0 \\
20 \\
\ldots \\
\ldots \\
\ldots \\
\dddot{0} \\
0 \\
0 \\
11 \\
40 \\
13 \\
0 \\
0 \\
0 \\
0 \\
34 \\
0 \\
0\end{array}$ & $\begin{array}{r}3 \\
0 \\
0 \\
38 \\
40 \\
1 \\
0 \\
38 \\
21 \\
40 \\
38 \\
0 \\
7 \\
0 \\
40 \\
40 \\
1 \\
1 \\
0 \\
0 \\
19 \\
0 \\
0 \\
0 \\
0 \\
40 \\
1 \\
0 \\
0 \\
26\end{array}$ & 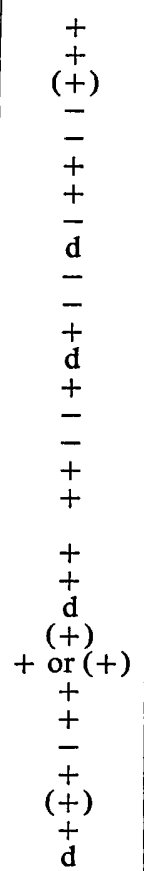 & $\begin{array}{l}\text { Read at } 1 \text { day } \\
\text { Weak reaction in } 2-3 \text { days } \\
\text { Read at } 2 \text { days } \\
\text { Weak reactions } \\
\text { Weak reactions } \\
\text { Negative after } 7 \text { days } \\
\text { Positive in } 2-5 \text { days } \\
\text { Read at } 2 \text { days } \\
\text { Read at } 2 \text { days }\end{array}$ \\
\hline
\end{tabular}

$+=$ Positive reaction in $1-2$ days; $(+)=$ delayed positive reaction; $d=$ reaction differs between strains; $-=$ negative reaction.

The representatives of named enterobacterial groups were first tested with each antiserum at a dilution of 1 in 20 . If agglutination took place at this dilution, the titre of the reaction was determined.

The strains under investigation were also tested with salmonella polyvalent $\mathrm{O}$ - and $\mathrm{H}$ antisera (Difco).

\section{RESULTS}

The biochemical reactions of the strains are listed in table I. All of the organisms produced pale colonies on MacConkey agar after overnight incubation, but the colonies began to turn pink after further incubation. This is 
consistent with their fermentation of lactose in a fluid medium after 2-3 days. Only one strain failed to produce gas from glucose and it also failed to reduce nitrate. Urease production, arginine desimidase activity and the fermentation of sucrose and dulcitol were variable characters, but the organisms showed remarkable consistency in their other biochemical reactions.

Antibiotic sensitivity tests showed that the strains were uniformly resistant to ampicillin, and sensitive to cephaloridine, kanamycin, gentamicin, neomycin, colistin and nitrofurantoin. Several strains were resistant to streptomycin and some strains showed mixed populations of streptomycin-resistant and streptomycin-sensitive cells. Three strains were resistant to chloramphenicol and tetracycline and two were resistant to nalidixic acid. Organisms were considered sensitive when the zones of inhibition were comparable in size to those produced by sensitive control organisms. Resistant organisms either showed no inhibition zones round the discs tested or, in the case of tetracycline, no zone round the $5-\mu \mathrm{g}$ disc and a zone less than $12 \mathrm{~mm}$ round the $30-\mu \mathrm{g}$ disc.

Twenty-seven of the organisms reacted with one or other of the four Oantisera. Nineteen of these strains appeared to belong to a single O-group. The results of the agglutination tests with the four $\mathrm{H}$-antisera were difficult to interpret because repeated tests with different batches of antigen prepared from the same organism showed considerable variation in the titres. Examination of two of the immunising strains under the electron microscope showed many fimbriae as well as peritrichous flagella. The presence of fimbriae might account for the apparent variation in H-antibody titres.

The prepared O-antisera did not agglutinate any of the other enteric organisms tested. One of the $\mathrm{H}$-antisera agglutinated Pr. mirabilis to a titre of only 40, its titre with the homologous organism being 5000 . None of the 40 strains under investigation agglutinated with the salmonella polyvalent $\mathrm{O}$ antiserum and one strain gave an agglutination with the salmonella polyvalent $\mathrm{H}$-antiserum at a dilution of 1 in 10 .

\section{Discussion}

The organisms under study possess the biochemical characters of the family Enterobacteriaceae as outlined in the Report of the International Subcommittee on Taxonomy of the Enterobacteriaceae (1963). They grow on ordinary media, reduce nitrate to nitrite, give a negative oxidase reaction and break down carbohydrates by a fermentative reaction. The two strains that were examined under the electron microscope had peritrichous flagella. The organisms form a homogeneous biochemical group, the minor differences in biochemical properties being within the limits of species variation.

The biochemical pattern of the group does not correspond exactly to that of any of the currently recognised genera in the Enterobacteriaceae (table II), but we feel that our strains most closely resemble the Salmonella-ArizonaCitrobacter division. In 1932 Werkman and Gillen examined 15 strains of citrate-positive coli-aerogenes intermediates that converted glycerol into trimethylene glycol. They proposed that the group be recognised as a new genus 
called Citrobacter containing seven species. Two of their strains were classified as $C$. freundii and four were grouped as $C$. intermedium. The differences between the two species were the failure of $C$. intermedium to produce hydrogen sulphide and indole, and to ferment aesculin, raffinose, salicin and sucrose. Although $C$. freundii became established, the remaining six species did not. Vaughn and Levine (1942) pointed out fallacies in some of the earlier methods used to classify the "intermediate" group and put forward a scheme to differentiate it from Escherichia and Aerobacter. However, they considered the group to be most closely related to Escherichia and proposed that strains

TABLE II

Comparison of the biochemical properties of other enterobacteria with those of the group under investigation

\begin{tabular}{l|c|c|c|c|c}
\hline \multirow{2}{*}{ Test } & \multicolumn{5}{|c}{ Reactions of } \\
\cline { 2 - 6 } & $\begin{array}{c}\text { Escherichia, } \\
\text { Shigella }\end{array}$ & $\begin{array}{c}\text { Salmonella, } \\
\text { Citrobacter, } \\
\text { Arizona }\end{array}$ & $\begin{array}{c}\text { Klebsiella, } \\
\text { Enterobacter, } \\
\text { Serratia }\end{array}$ & $\begin{array}{c}\text { Proteus, } \\
\text { Providencia }\end{array}$ & $\begin{array}{c}\text { Group under } \\
\text { investigation }\end{array}$ \\
\hline $\begin{array}{l}\text { Indole production } \\
H_{2} \text { S production TS1 }\end{array}$ & - & - & - & $\mathrm{d}$ & + \\
$\begin{array}{l}\text { Gluconate oxidation } \\
\begin{array}{l}\text { Citrate utilisation } \\
\text { Phenylalanine } \\
\text { deamination }\end{array}\end{array}$ & - & + & - & $\frac{\mathrm{d}}{\mathrm{d}}$ & \pm \\
$\begin{array}{l}\text { Methyl red reaction } \\
\text { Voges-Proskauer reaction }\end{array}$ & - & + & + & - & + \\
\hline
\end{tabular}

$+=$ Positive reaction; $-=$ negative reaction; $\mathrm{d}=$ reaction differs between strains.

producing hydrogen sulphide be called $E$. freundii and strains negative in this respect be called $E$. intermedium. This classification was not widely used by later workers, and Edwards and Ewing (1962) altered the criteria for C. freundii, allowing strains previously called $C$. intermedium to be included in this species.

Several recent papers report groups of organisms similar to the strains described here. It would seem that our strains most closely resemble the organisms described by Washington, Yu and Martin (1969), Young, Kenton and Moody (1970) and Frederiksen (1970).

Washington et al. (1969) called their cultures atypical strains of Enterobacter cloacae. Table III shows the major differences between the biochemical reactions of E. cloacae, as given by Edwards and Ewing, and the reactions of the strains described here. The sensitivity of our organisms to cephalosporin C is another feature that tends to exclude them from the Enterobacter genus. Fleming, Charlebois and Dunmore (1970) found that Enterobacter strains produce cephalosporinase and are resistant to cephalosporin at a concentration of $500 \mu \mathrm{g}$ per $\mathrm{ml}$. We feel that these differences are too great to allow the organisms to be classified in the Enterobacter genus.

Young et al. proposed the establishment of a new genus Levinia for these

J. MED. MICROBIOL.-VOL. 4 (1971) 
organisms, and pointed out differences that they felt distinguish the group from the genus Citrobacter. The distinguishing characters of Levinia include the inability to produce hydrogen sulphide from TS1 and the consistent production of indole, arginine " dihydrolase" and ornithine decarboxylase.

Frederiksen compared the biochemical reactions of a group of 30 organisms with the reactions of $E$. coli, C. freundii and strain ATCC 6750. The latter organism is accepted as the authentic M8B strain of Werkman and Gillen, who placed it in the species $C$. intermedium. Frederiksen considers that $C$. intermedium must be regarded as a later synonym of $C$. freundii. He feels that

TABLE III

Differences in properties between Enterobacter cloacae and the group under investigation

\begin{tabular}{l|c|c}
\hline \multirow{2}{*}{ Test } & \multicolumn{2}{|c}{ Reactions of } \\
\cline { 2 - 3 } & $\begin{array}{c}\text { Enterobacter } \\
\text { cloacae }\end{array}$ & $\begin{array}{c}\text { Group under } \\
\text { investigation }\end{array}$ \\
\hline $\begin{array}{l}\text { Indole production } \\
\text { Gluconate oxidation }\end{array}$ & - & + \\
$\begin{array}{l}\text { Gelatin liquefaction } \\
\text { Methyl red reaction }\end{array}$ & + & - \\
Voges-Proskauer reaction & $(+)$ & + \\
$\begin{array}{l}\text { Acid produced from: } \\
\text { adonitol } \\
\text { dulcitol } \\
\text { inositol } \\
\text { raffinose } \\
\text { sucrose }\end{array}$ & + & + \\
Sensitivity to cephalosporin C & $\mathrm{d}$ & + \\
\hline
\end{tabular}

$+=$ Positive reaction in $1-2$ days; $(+)=$ delayed positive reaction; $\mathbf{d}=$ reaction differs between strains; $-=$ negative reaction.

the strains he describes should be included in the genus Citrobacter, but that they are sufficiently different from $C$. freundii to be classified as a separate species that he proposes to call C. koseri. In this paper, groups of organisms described by other workers are mentioned. These differ somewhat from Frederiksen's strains, but could still be assigned to the genus Citrobacter. Similar groups have been described by Washington et al. (1970) as hydrogen sulphide-negative variants of Citrobacter and by Slifkin and Engwall (1969) as C. intermedium. These two groups of organisms resemble each other closely, but differ from the strains described here by fermenting raffinose, failing to produce indole and failing to ferment adonitol and inositol. It is clear that a detailed comparative study of these organisms is required to determine their taxonomic status.

All strains included in this investigation were resistant to ampicillin. Strains isolated during the early part of the study were sensitive to the other antibiotics tested, but strains resistant to several antibiotics were encountered later in the investigation. Washington et al. (1969) found their atypical E. cloacae strains 
to be resistant to ampicillin. Frederiksen does not record the antibiotic sensitivities of his strains. The groups described by Slifkin and Engwall and by Washington et al. (1970), as well as differing biochemically from our strains, have a greater susceptibility to ampicillin.

The somatic antigens of our strains were heterogeneous and the results with flagellar antigens were inconclusive. In the limited studies performed, no antigenic relationship was found between these organisms and other members of the family Enterobacteriaceae.

Our organisms appeared to act mainly as secondary invaders. Twenty-five of our strains were isolated from urine, four from sputum, four from pressure sores and the remaining seven from a variety of other sites. Factors predisposing to infection, such as paraplegia and malignant disease, were present in at least 21 of our patients. Similar findings are recorded by Slifkin and Engwall and by Washington et al. (1969, 1970).

It seems clear that since organisms of this type are being isolated with greater frequency from clinical specimens, their taxonomic position should be clarified. We feel that the group described here belongs to the SalmonellaArizona-Citrobacter division and agree with Frederiksen's proposal that such organisms be regarded as a species of Citrobacter.

\section{SUMMARY}

Forty strains of enteric bacilli were studied in detail. Biochemically the organisms form a homogeneous group belonging to the family Enterobacteriaceae, but they do not fit into any of the recognised groups. The following pattern of biochemical reactions was recorded. The strains produced indole, utilised citrate and malonate, and decarboxylated ornithine. They failed to produce hydrogen sulphide on TS1, to deaminate phenylalanine or to decarboxylate lysine. The Voges-Proskauer reaction was negative. Acid was produced from adonitol, arabinose, maltose, mannitol, rhamnose and sorbitol in 2 days. Lactose fermentation was delayed. Acid was not produced from raffinose. Preliminary serological studies showed no cross-reactions between these strains and other members of the Enterobacteriaceae. It is felt that this group should be assigned to a new species in the genus Citrobacter.

We wish to thank Miss N. Anderson for carrying out the electron microscopy, Miss P. Missett for technical assistance and Dr I. B. R. Duncan for advice and criticism during preparation of this paper.

\section{REFERENCES}

CowAN, S. T., AND STEEL, K. J. 1965. Manual for the identification of medical bacteria, Cambridge.

EDwards, P. R., AND EwING, W. H. 1962. Identification of Enterobacteriaceae, 2nd ed., Minneapolis.

Fleming, P. C., Charlebois, Margaret, and Dunmore, R. T. 1970. The use of cephalosporin $\mathrm{C}$ in the identification of the Enterobacteriaceae. Postgrad. Med. J., 46, Supplement (October), p. 51.

FREDERIKSEN, W. 1970. Citrobacter koseri, a new species within the genus Citrobacter, with a comment on the taxonomic position of Citrobacter intermedium (Werkman and Gillen). Spisy přir. Fak. Univ. Brne, 47, 89. 


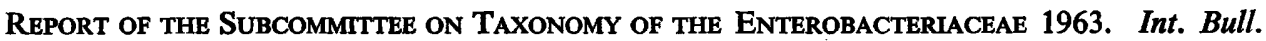
Bact. Nomencl. Taxon., 13, 69.

Slifkin, M., and Engwall, CaRol 1969. The clinical significance of Citrobacter intermedium. Amer. J. Clin. Path., 52, 351.

THORNLEY, M. J. 1960. The differentiation of Pseudomonas from other gram-negative bacteria on the basis of arginine metabolism. J. Appl. Bact., 23, 37.

Vaughn, R. H., and Levine, M. 1942. Differentiation of the "intermediate" coli-like bacteria. J. Bact., 44, 487.

Washington, J. A., I, Yu, Pauline K. W., and Martin, W. J. 1969. Biochemical and clinical characteristics and antibiotic susceptibility of atypical Enterobacter cloacae. Appl. Microbiol., 17, 843.

Washington, J. A., II, Yu, Pauline K. W., and Martin, W. J. 1970. Hydrogen sulfidenegative variant of Citrobacter. Appl. Microbiol., 20, 587.

Werkman, C. H., AND Gillen, G. F. 1932. Bacteria producing trimethylene glycol. J. Bact., 23, 167.

Young, Viola M., Kenton, D. M., AND Moody, M. R. 1970. Levinia, a new genus of the family Enterobacteriaceae recovered from patient samples. Abstracts, $\mathrm{X}$ International Congress for Microbiology, Mexico City, p. 192. 